\title{
Hatching Distribution of Eggs Varying in Weight and Breeder Age
}

\section{Author(s)}

Vieira SL

Almeida JG

Lima AR

Conde ORA

Olmos AR

Departamento de Zootecnia

Universidade Federal do Rio Grande do Sul

Mail Address

Sergio Luiz Vieira

Departamento de Zootecnia

Universidade Federal do Rio Grande do Sul

Av. Bento Gonçalves, 7712

91.540-000. Porto Alegre, RS

Email: slvieira@ufrgs.br

\section{Keywords}

breeder age, egg weight, and hatchability

Supported by FAPERGS.

\section{ABSTRACT}

Broiler chicks from one incubator hatch within long periods of time, which leads to dehydration and reduction in yolk sac reserves of those chicks that have hatched earlier and potentially impairs early performance. The present research investigated the hatching distribution at intervals of incubation using eggs of different weights within one breeder age or eggs from widely different breeder ages. Eggs from breeders at 27 and 59 weeks of age ( 54 and $69 \mathrm{~g}$ ) and from breeders at 40 weeks of age, which were graded as light ( $58 \mathrm{~g})$ and heavy $(73 \mathrm{~g})$, were placed in a commercial incubator. There were a total of 1,184 eggs distributed in four treatments and eight replicates: eggs from 27week-old breeders (27B), eggs from 59-week-old breeders (59B), light eggs from 40-week-old breeders (40BL) and heavy eggs from 40-weekold breeders $(40 \mathrm{BH})$. Replicates were comprised of 37 eggs that were placed in each incubator tray. The treatments were physically separated from each other using a plate. Eggs were transferred to a hatcher after 432 hours of incubation and the first chick hatched at 449 hours of incubation. Afterwards, the number of completely hatched chicks from each replicate was recorded at six-hour intervals until 503 hours of incubation, when the hatchings stopped. Hatched chicks were removed from the trays after each measurement. Data were submitted to an analysis of variance with repeated measures. There was a significant interaction between breeder age and incubation length. The hatching onset of eggs from the old breeders was later compared to young breeders. Hatchability (\% incubated eggs) was lower for the old breeders; however, differences in hatchability as a percentage of the hatched eggs were not so evident. Complete hatchability occurred only at 503 hours of incubation; however, more than $90 \%$ eggs had hatched 18 hours earlier.

\section{INTRODUCTION}

In commercial operations, chicks are usually removed from hatchers after 504 hours of incubation. This has been regarded as an optimum length of time to maximize the hatching of incubated eggs. However, the window of time between the hatching of the first and the last chick is greater than 48 hours in any group of eggs (Sklan et al., 2000). Therefore, groups of chicks originated from any batch of eggs set together in the incubator show high variability in the number of hours spent between hatching and placement in the broiler house.

Wyatt et al. (1985), Nir \& Levanon (1993), and Sklan et al. (2000) observed reductions of $32 \%$ in the weight of chicks that remained in the incubator for 32 hours after hatching. Losses due to starvation and dehydration are related to the time that the chicks are left in the hatcher before placement (Fanguy et al., 1980; Wyatt et al., 1985). Delays 
between hatching and placement also lead to permanent losses in live performance and breast meat yield at market age (Vieira \& Moran, 1999a; Halevy et al., 2000). In this regard, research has clearly demonstrated the benefits of allowing the chicks to eat and drink as soon as possible after hatching, such as improvements in several characteristics of live performance, digestive metabolism and meat yield (Noy \& Sklan, 1995; Uni et al., 1995).

Early chick performance is influenced by egg source, since egg weight and chick weight at hatching are highly correlated (Halbersleben \& Mussehl, 1922). Embryo size before hatching and at hatching may be altered by egg weight and incubation environment, regardless of the avian species (Wilson, 1991). After hatching, however, the effect of egg weight decreases with the age of the progeny (O'Neil, 1955).

Egg contents vary according to breeder age, but also to egg weight within any breeder age (Vieira \& Moran, 1998a; Vieira \& Moran, 1998b). Yolk percentage increases in eggs as the breeders age, but is decreased in heavy eggs sorted from those produced within any breeder age. In chicken eggs, the total incubation period needed to produce a complete embryo might depend on contents differences (Shanawany, 1987). Therefore, alterations in egg contents, which affect hatching time, may be correlated to egg weight and breeder age. This study was conducted with the objective of evaluating the incubation period needed to the complete hatching of eggs originating from breeders varying widely in age and eggs from breeders with the same age but varying in weight.

\section{MATERIAL AND METHODS}

This study was conducted in a commercial hatchery using a multiple stage Cumberland incubator and a Rooster hatcher. Eggs were sampled from Ross vs. Ross 308 breeders aged 27, 40 and 59 weeks housed in the same breeder farm. All eggs were collected within the same period of time, and therefore time elapsed between oviposition and placement in the incubator was similar between the different egg sources. After placement in the incubator, eggs were turned hourly from 0 to 18 days. Eggs were transferred to hatchers after 18 days. Temperature was $37.4^{\circ} \mathrm{C}$ in the incubator and $36.8^{\circ} \mathrm{C}$ in the hatcher. Relative humidity settings in the incubator and hatcher were 56 and $70 \%$, respectively.

The following egg sources (treatments) were used: 27 week-old breeders (27B), 59 week-old breeders
(59B), light eggs from 40 week-old breeders (40BL) and heavy eggs from 40 week-old breeders $(40 \mathrm{BH})$. There were 296 eggs set to incubate per treatment, and eight replicates per treatment (37 eggs each). Mean weight and standard deviations of eggs from breeders with 27 and 59 weeks of age were $54.1 \pm 4.4$ and $69.1 \pm$ $4.7 \mathrm{~g}$, respectively. Eggs from forty-week-old breeders were graded as light and heavy and mean weights were $57.7 \pm 1.8$ and $72.7 \pm 2.5 \mathrm{~g}$, respectively. A sample of 90 eggs from each treatment was weighed, and their contents were separated and weighed as yolk, albumen and shell.

A completely randomized design was used. A metal plate physically separated replicates in each incubator tray. At 18 days, the eggs were transferred from the incubator to the hatcher and placed also as replicate groups in the corresponding tray level in the hatcher. Chicks completely hatched from each replicate were recorded from the moment the first chick hatched (449 hours) and every six hours afterwards until hatchings completed ceased (503 hours).

Hatched chicks were removed from the hatcher after each measurement and were immediately feather-sexed and killed by cervical dislocation. Chick carcass and yolk sac were separated and weighed.

In this study, the model included "time", so that "time" was the six-hour periods (incubation lengths) at which the completely hatched chicks were taken from the hatcher. Therefore, it was possible to separate time effects from breeder source effects and to evaluate the interaction between these two sources of variation. This objective was accomplished by submitting the data to an Analysis of Variance with repeated measures using the Proc Mixed procedure of SAS (1998). Variance and covariance were chosen for this analysis in accordance to the Akaike (1987) criteria. The data structure that produced the best adequacy for data analysis was a first-order auto regressive analysis, which admits heterogeneity of variances and also a larger existing correlation between measurements taken at adjacent periods. Results are presented as cumulative hatchability, expressed as percentage of incubated eggs and as percentage of hatched chicks. Therefore, it is possible to visually separate confounding effects due to egg source such as hen age, which is known to interfere with the hatchability of incubated eggs. Mean differences were separated using the Tukey's test and are presented for the isolated factors as well as for the interaction between factors. 


\section{RESULTS AND DISCUSSION}

The weights of eggs and egg components are presented in Table 1. Eggs from breeders aged 59 weeks were heavier and showed greater proportions of yolk when compared to eggs from the breeders with 27 weeks of age. However, eggs from breeders aged 40 weeks and graded as heavy were the heaviest between all treatments, but the proportion of yolk was not different between eggs of forty-week-old breeders and fifty-nine-week-old breeders. Heavier eggs produced heavier chicks. Yolk sac proportion was similar between chicks from the two treatments with low egg weight (27B and 40BL), but it was lower when compared to chicks from heavy eggs (40BH and $59 \mathrm{~B}$ ) of both breeder ages. However, yolk sacs from $40 \mathrm{BH}$ chicks were greater in proportion than those from chicks from 59B (Table 3). Information corroborating these findings is widely known and has been extensively reviewed (Shanawany, 1987; Vieira \& Moran, 1999b).

\begin{tabular}{|c|c|c|c|c|}
\hline Egg source & Egg Weight, g & Yolk, \% & Albumen, \% & Shell, \% \\
\hline $27 \mathrm{~B}$ & $54^{d}$ & $26.9 \mathrm{~b}$ & $61.3^{a}$ & $11.8 \mathrm{ab}$ \\
\hline $59 \mathrm{~B}$ & $69^{b}$ & $34.1^{\mathrm{a}}$ & $54.5^{c}$ & $11.4^{c}$ \\
\hline $40 \mathrm{BL}$ & $58^{c}$ & $31.4{ }^{a b}$ & $56.7^{c}$ & $11.9^{a}$ \\
\hline $40 \mathrm{BH}$ & $73^{a}$ & 29.7 ab & $58.8^{b}$ & $11.5^{b}$ \\
\hline Probability & 0.0001 & 0.0064 & 0.0001 & 0.0018 \\
\hline$C V, \%$ & 5.76 & 52.03 & 5.53 & 7.74 \\
\hline
\end{tabular}

Means followed by the same letter within a column are not different according to Tukey's test.

Table 2 - Hatchability (\% incubated eggs) of eggs originated from breeders of widely different ages (27 and 59 weeks) or graded according to weight within one breeder age (40 weeks).

\begin{tabular}{cc} 
Egg source & Hatchability, \% \\
$27 \mathrm{~B}$ & $88.3^{\mathrm{a}}$ \\
$59 \mathrm{~B}$ & $73.5^{\mathrm{b}}$ \\
$40 \mathrm{BL}$ & $82.3^{\mathrm{ab}}$ \\
$40 \mathrm{BH}$ & $82.7^{\mathrm{ab}}$ \\
Probability & 0.0007 \\
C.V., \% & 7.86 \\
\hline
\end{tabular}

Means followed by the same letter within a column are not different according to Tukey's test.

Hatchability of eggs from the different sources used in this experiment showed the highest and lowest values for the younger and older breeders, respectively. Intermediate values were seen in the fortyweek-old breeders, regardless of egg weight (Table 2). Eggs from old breeders are known to have an overall reduction in hatchability when compared to those from young breeders, which is mostly related with increased embryo mortality and reduction in fertility (Reis et al., 1997; Lapao et al., 1999; Hudson et al., 2004). Therefore, this is always a confounding source for the numeric interpretation of hatchability of incubated eggs when comparing breeders at different ages. Thus, hatchability data expressed as a percentage of hatched eggs eliminates this confounding element and allows for numeric estimations on the same basis.

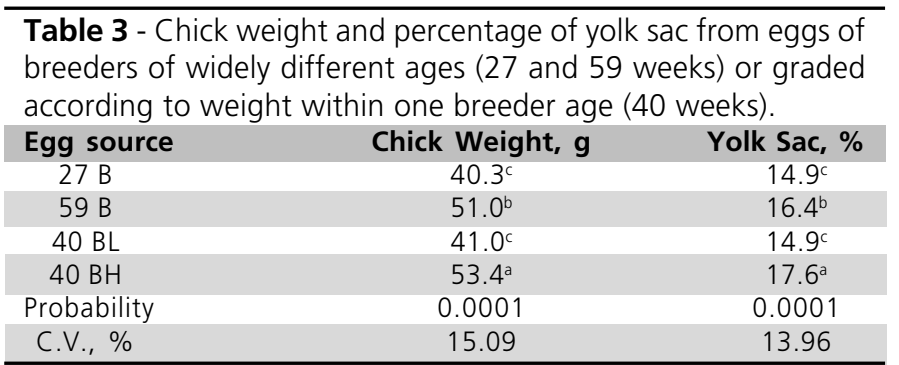

Means followed by the same letter within a column are not different according to Tukey's test.

Results presented in Tables 4 and 5 and Figures 1 and 2 demonstrate diversity in hatching patterns for chicks originated from breeders producing heavy eggs compared to light eggs, regardless of age. Overall, light eggs initiated to hatch earlier and produced chicks in a wider range of time between the first and the last hatched chick than heavy eggs. Most of the differences in hatchability patterns seen between heavy and light eggs, irrespective of breeder age, were observed between 467 and 485 hours of incubation.A slower rate of hatchability was seen for heavy eggs during this period on the basis of hatched chicks; nevertheless, differences disappeared afterwards.

Several factors, such as genetics and environment, have been reported to affect hatchability. Nevertheless, results are not consistent in many cases, and the nature of the effect on hatchability is not clearly evident in others (Bohren et al., 1961). Although reduction in incubation length has not been specifically targeted in genetic improvement, it may have occurred in the chicken by unconscious selection following selection for egg size (Bohren et al., 1961). Lerner \& Gunns (1952) have demonstrated in flocks selected for large egg size that the eggs with optimum hatchability were usually below the mean egg size of the population. Therefore, the total period of incubation needed to produce a complete and viable embryo may be longer nowadays than in the past, since the mean egg weight has increased in the current genetic lines. 
Table 4 - Cumulative hatchability of eggs from breeders of widely different ages (27 and 59 weeks) or graded according to weight within one breeder age (40 weeks), \% incubated eggs.

\begin{tabular}{|c|c|c|c|c|c|}
\hline \multirow{3}{*}{$\begin{array}{l}\text { Incubation } \\
\text { length (hours) }\end{array}$} & \multicolumn{4}{|c|}{ Egg source } & \\
\hline & $29 B$ & $59 \mathrm{~B}$ & $40 \mathrm{BL}$ & \multirow{2}{*}{\multicolumn{2}{|c|}{$\begin{array}{l}40 \mathrm{BH} \text { Incubation } \\
\text { length mean }\end{array}$}} \\
\hline & 0 & 0 & 0.9 & 0 & \\
\hline 455 & 0 & 0 & 0.9 & 0 & $0.2 d$ \\
\hline 461 & 2.0 & 0 & 3.3 & 1.0 & $1.6 \mathrm{~d}$ \\
\hline 467 & $9.9^{a}$ & $2.6^{b}$ & $9.3^{a}$ & $6.1^{a b}$ & $7.0 \mathrm{~d}$ \\
\hline 473 & $29.5^{\text {a }}$ & $15.6^{b}$ & $26.6^{a}$ & $18.8^{b}$ & $22.6 \mathrm{c}$ \\
\hline 479 & $60.1^{\mathrm{a}}$ & $45.1^{b}$ & $59.6^{a}$ & $45.1^{b}$ & $52.5 \mathrm{~b}$ \\
\hline 485 & $81.8^{a}$ & $66.3^{b}$ & $76.0^{a}$ & $75.0^{a b}$ & $74.8 \mathrm{a}$ \\
\hline 491 & $87.3^{a}$ & $72.5^{b}$ & $82.0^{a}$ & $82.3^{a}$ & $81.0 \mathrm{a}$ \\
\hline 497 & $87.9^{a}$ & $73.5^{b}$ & $82.3 a b$ & $82.3 a b$ & $81.5 \mathrm{a}$ \\
\hline 503 & $88.3^{a}$ & $73.5^{b}$ & $82.3 \mathrm{ab}$ & $82.6 \mathrm{ab}$ & 81.7 \\
\hline \multicolumn{6}{|l|}{ Egg source } \\
\hline mean & $44.7 \mathrm{a}$ & $\begin{array}{r}34.9 \mathrm{c} \\
\text { Prob }\end{array}$ & $\begin{array}{l}42.3 \mathrm{ab} \\
\text { bility }\end{array}$ & $39.3 \mathrm{~b}$ & \\
\hline \multicolumn{2}{|c|}{ Egg source } & \multicolumn{2}{|c|}{0.0062} & & \\
\hline \multicolumn{2}{|c|}{ Incubation length } & \multicolumn{2}{|c|}{0.0001} & & \\
\hline \multicolumn{2}{|c|}{ Interaction } & \multicolumn{2}{|c|}{0.0449} & & \\
\hline
\end{tabular}

Means followed by the same letter within incubation length are not different according to Tukey's test.

Table 5 - Cumulative hatchability of eggs from breeders of widely different ages (27 and 59 weeks) or graded according to weight within one breeder age (40 weeks), \% hatched eggs.

\begin{tabular}{|c|c|c|c|c|c|}
\hline \multirow{3}{*}{$\begin{array}{l}\text { Incubation } \\
\text { length (hours } \\
449\end{array}$} & \multicolumn{4}{|c|}{ Egg source } & \multirow[b]{2}{*}{$\begin{array}{l}\text { Incubation } \\
\text { th mean }\end{array}$} \\
\hline & s) & 59 B & $40 \mathrm{BL}$ & $\begin{array}{c}40 \mathrm{BH} \\
\text { leng }\end{array}$ & \\
\hline & 0 & 0 & 0.9 & 0 & $0.2 f$ \\
\hline 455 & 0 & 0 & 0.9 & 0 & $0.2 f$ \\
\hline 461 & 2.3 & 0 & 3.8 & 1.4 & 1.9 ef \\
\hline 467 & $10.9^{a}$ & $3.8^{\mathrm{b}}$ & $11.1^{\mathrm{a}}$ & $8.1^{\mathrm{ab}}$ & $8.5 \mathrm{e}$ \\
\hline 473 & $33.0^{a}$ & $21.1^{\mathrm{b}}$ & $32.4^{\mathrm{a}}$ & $23.1^{\mathrm{b}}$ & $27.4 d$ \\
\hline 479 & $67.6 \mathrm{ab}$ & $61.4^{b c}$ & $72.4^{a}$ & $54.6^{c}$ & $64.0 \mathrm{c}$ \\
\hline 485 & 92.6 & 90.1 & 92.0 & 90.8 & $91.4 \mathrm{~b}$ \\
\hline 491 & 98.9 & 98.5 & 99.6 & 99.5 & $99.1 \mathrm{a}$ \\
\hline 497 & 99.6 & 100.0 & 100.0 & 99.5 & 99.8 a \\
\hline 503 & 100.0 & 100.0 & 100.0 & 100.0 & 100.0 \\
\hline $\begin{array}{l}\text { Egg source } \\
\text { mean }\end{array}$ & $50.5 a b$ & $\begin{array}{r}47.5 \mathrm{~b} \\
\text { Prob }\end{array}$ & $\begin{array}{l}51.3 \text { a } \\
\text { ability }\end{array}$ & $47.7 \mathrm{~b}$ & \\
\hline Egg source & & & 0.0121 & & \\
\hline Incubation len & igth & & 0.0001 & & \\
\hline Interaction & & .7016 & & & \\
\hline
\end{tabular}

Means followed by the same letter within incubation length are not different according to Tukey's test.

Reported results show a great deal of contradiction regarding the relation between incubation time and egg source. At least part of the difficulty in comparing research in this area is related to the type of measurements taken by each author. Incubation time has been defined as the average number of hours of the first to the last chick to hatch, but has also been confounded with the distribution of hatched chicks within a period of time. In the present study, authors were interested in searching for differences between

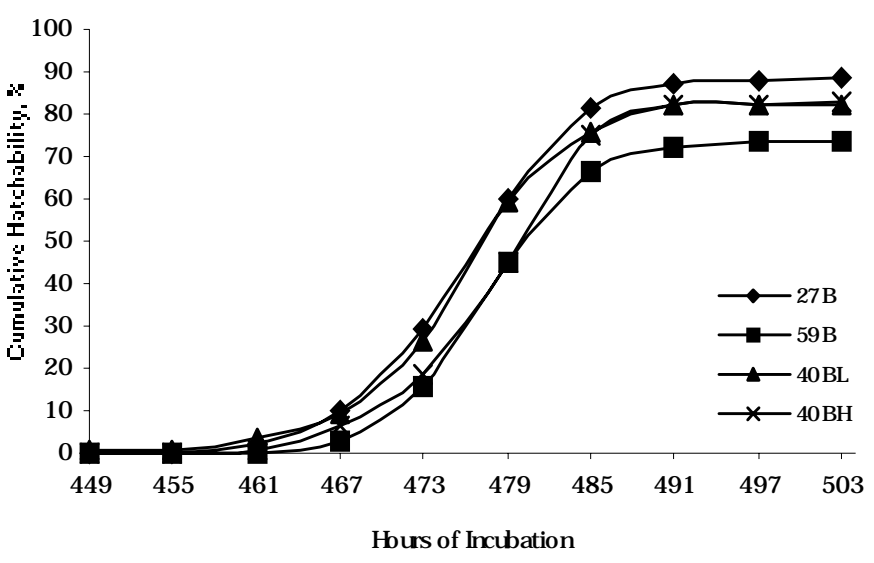

Figure 1 - Cumulative hatchability of eggs from breeders of widely different ages ( 27 and 59 weeks) or graded according to weight within one breeder age (40 weeks), \% incubated eggs.

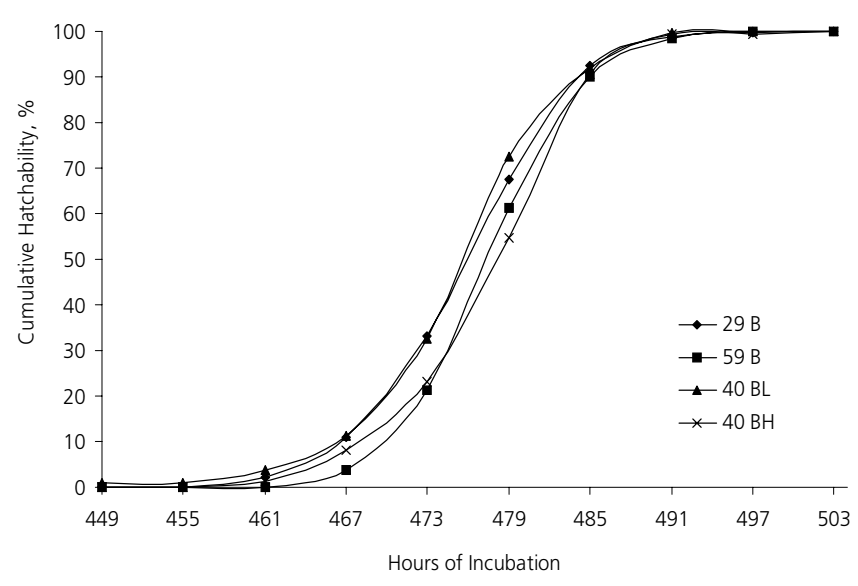

Figure 2 - Cumulative hatchability of eggs from breeders of widely different ages (27 and 59 weeks) or graded according to weight within one breeder age (40 weeks), \% hatched eggs.

the distributions of hatching that were affected by egg sources. Since the time lag between the hatching of the first and the last chick may be long, this may be an important factor affecting early chick performance. Incubation period have been found to lengthen (Olsen, 1942; Williams et al., 1951, Hudson et al., 2004) to shorten (McNally \& Byerly, 1936; Smith \& Bohren, 1975; Burton \& Tullet, 1985) or not to change (Reis et al., 1997) with the aging of hens and the consequent increases in egg size. Variations in incubation length may be related to breed and line within breed and therefore this trait may be altered by selection (Crittenden \& Bohren, 1961; Smith \& Bohren, 1975). Studies in this matter should always consider similar periods between oviposition and setting in incubators since pre-incubation storage time affects the incubation period (MacLaury \& Insko, 1968; Reis et al., 1997). 
The time spent until the hatching onset may not be correlated with incubation length. Reis et al. (1997) reported that hen age did not change hatching distribution during the incubation period. However, a delay of hatching onset has been reported in light eggs from young hens when compared to heavy eggs from old hens (Hudson et al., 2004). Differences in terms of embryo development and embryo metabolic rates during incubation, as well as reduced gas exchange due to superior albumen quality of eggs from young breeders are considered as possible reasons for the earlier hatching of chicks from heavy eggs (Mather \& Laughlin, 1979; Brake et al., 1997). In our study, chicks from light eggs began to hatch earlier. Since the preincubation period between egg sources and genetics were potentially the same for the breeders used, speculation on the reasons for our findings are open and may be related to other factors, such as external environment. Increased ambient temperature in Brazil when compared to studies from temperate countries may have an impact on acceleration of embryo development. This effect is likely to be greater in light eggs because of their reduced volume and mass.

Data from this study allow generalizations in terms of the total time needed to collect chicks of diverse egg sources from the hatcher. Chicks from larger eggs are expected to hatch closer to the moment in which they are removed from the hatcher when compared to chicks originated from breeders that are 40 weeksold or younger.This may improve early chick performance due to reduced dehydration of chicks from heavier eggs, which adds on to the natural advantage of larger than smaller chicks in most of the commercial hatchers running on a 504-hour incubation period.

In spite of the different egg sources, a maximum cumulative hatchability was seen between 497 and 503 hours of incubation. However, more than $90 \%$ of eggs had already hatched at 485 hours, and less than $1 \%$ increase in hatchability occurred after 491 hours of incubation. Therefore, a delay of at least 12 hours was imposed on $99 \%$ of the chicks that had already hatched in order to gain $1 \%$ in hatchability. This involuntary starvation represents growth potential and meat production that have been wasted under the current hatchery practices. This finding is not new, but the numeric estimations from this study support a recommendation to remove chicks out of the hatcher at least once before the traditionally used period of 504 hours of incubation ( 21 days). Removing chicks that hatch earlier and providing them immediately with feed and water has been shown to improve subsequent growth compared to what is achieved by birds placed with those that hatch later (Hager \& Beane, 1983; Fanguy et al., 1980; Kingston, 1979; Williams et al., 1951; Wyatt et al, 1985).

Yolk sac is important during the transition from the embryonic to independent life. It is especially important until 3 days of age, when the bird is expected to be completely adapted to the external environment. Heavier eggs originate heavier yolk sacs, but proportions are expected to be similar (Vieira \& Moran, 1998a; Vieira \& Moran, 1998b). In the present study, however, major differences were found between egg sources, so that chicks originated from heavy eggs had higher yolk sac percentages when compared to chicks from light eggs. Difference was also observable between heavy eggs in favor of chicks from $40 \mathrm{BH}$ hens, which is not usually seen. A greater proportion of yolk sac represents increased amounts of energy and nutrients, but also passive immunity, which protects the chicks against microbiological challenges experienced by the breeder (Vieira \& Moran, 1998a; Vieira \& Moran, 1998b, Vieira \& Moran, 1999a). This characteristic, as well as the reduced range in hatching time, also supports the benefits obtained with chicks from heavier eggs and may be related with the better response in performance and early survival of heavy chicks compared to light chicks.

\section{CONCLUSIONS}

In this experiment $90 \%$ of the chicks hatched within 485 hours of incubation or less. Therefore, it is suggested that hatcheries should remove chicks from the hatchers at least once before 504 hours, which is the traditionally used period. The period of starvation before placement with feed and water would be thus reduced for most of the hatched chicks.

Chicks from heavy eggs showed a delay to initiate hatching and a slower increase in hatchability to 479 hours of incubation when compared to chicks from light eggs. Therefore, they hatch within a narrower range of time, which may represent an advantage compared to the other egg sources due to a reduced number of chicks starving between hatching and placement.

\section{REFERENCES}

Akaike H. Factor-analysis and AIC. Psychometrika 1987; 52:317-332.

Bohren BB, Crittenden LB \& King RT. Hatching time and hatchability in the fowl. Poultry Science 1961; 40:620-633. 
Brake J, Walsh TJ, Benton CE, Pettite JN, Meijerhof R, Penalva G. Egg handling and storage. Poultry Science 1997; 76:144-151.

Burton FG \& Tullet SG. The effects of egg weight and shell porosity on the growth and water balance on the chicken embryo. Comparative Biochemistry and Physiology 1985; 81A:377-385.

Crittenden LB \& Bohren BB. The genetic and environmental effect of hatching time, egg weight and holding time on hatchability. Poultry Science 1961; 40:1736-1750.

Fanguy RC, Misra LK, Vo KV. Effect of delayed placement on growth performance of commercial broilers. Poultry Science 1980; 59:12151220.

Hager JE, Beane WL. Posthatch incubation time and early growth of broiler chickens. Poultry Science 1983; 62:247-254.

Halbersleben DL, Mussehl FE. The relation of egg weight to chick weight at hatching. Poultry Science 1922; 1:1443-144.

Halevy O, Geyra A, Barak M, Uni Z, Sklan D. Early posthatch starvation decreases satellite cell proliferation and skeletal muscle growth in chicks. Journal of Nutrition 2000; 130: 858-864.

Hudson BP, Dozier WA, Wilson JL, Sander JE, Ward TL. Reproductive performance and immune status of caged broiler breeder hens provided diets supplemented with either inorganic or organic sources of zinc from hatching to 65 wk of age. Journal of Applied Poultry Research 2004; 13:349-359.

Kingston DJ. Some hatchery factors involved in early chick mortality. Australian Veterinary Journal 1979; 55:418-421.

Lapao C, Gama LT, Soares MC. Effects of broiler breeder age and length of egg storage on albumen characteristics and hatchability. Poultry Science 1999; 78:640-645.

Lerner IM, Gunns CA. Egg size and reproductive fitness. Poultry Science 1952; 31:537-544.

Maclaur DW. \& Insko Jr WM. Relation of pre-incubation factors and post-hatching performance to length of incubation period. 1 . Effects of egg weight and storage time on length of incubation period. Poultry Science 1968; 47:305-311.

Mather CM \& Laughlin KF. Storage of hatched eggs: the interaction between parental age and early embryonic development. British Poultry Science 1979; 20:595-604.

McNally EH \& Byerly TC. Variation in the development o f embryos of hen eggs. Poultry Science 1936; 15:280-283.

Nir I, Levanon M. Effect of posthatch holding time performance and residual yolk and liver composition. Poultry Science 1993; 72: 1994-1997.

Noy Y, Sklan D. Digestion and absorption in the young chick. Poultry Science 1995; 74:366-373.
Olsen MW. The effect of age and weight of turkey eggs on the length of incubation period. Poultry Science 1942; 21:532-535.

O'Neil JB. Percentage size of chick at hatching and its relationship to growth and mortality. Poultry Science 1955; 34:761-764.

Reis LH, Gama LT, Soares MC. Effects of short storage conditions and broiler breeder age on hatchability, hatching time, and chick weights. Poultry Science 1997; 76:1459-1466.

SAS, 1998. SAS User's Guide: Statistics. SAS Institute Inc., Cary, NC

Shanawany MM. Hatching weight in relation to egg weight in domestic birds. Word's Poultry Science Association Journal 1987; 43:107-115.

Sklan D, Noy Y, Hoyzman A, Rozenboim I. Decreasing weight loss in the hatchery by feeding chicks and poults in hatching trays. Journal of Applied Poultry Research 2000; 9:142-148.

Smith KP \& Bohren BB. Age of pullets effect on hatching time, egg weight and hatchability. Poultry Science 1975; 54:959-963.

Uni Z, Noy Y, Sklan D. Posthacth changes in morphology and function of the small intestines in heavy- and light-strain chicks. Poultry Science 1995; 74:1622-1629.

Vieira SL, Moran ET. Comparison of eggs and chicks from broiler breeders of extremely different ages. Journal of Applied Poultry Research 1998a; 7:372-376.

Vieira SL, Moran ET. Broiler chicks hatched from egg weight extremes and diverse breeder strains. Journal of Applied Poultry Research 1998b; 7:392-402.

Vieira SL, Moran Jr ET. Effects of delayed placement and used litter on broiler yields. Journal of Applied Poultry Research 1999a; 8:7581.

Vieira SL, Moran Jr ET. Effects of egg origin and chick post-hatch nutrition on broiler live performance and meat yields. World's Poultry Science Journal 1999b, 55:125-142.

Williams C, Godfrey GF, Thompson RB. The effect of rapidity of hatching on growth, egg production, mortality and sex ratio in the domestic fowl. Poultry Science 1951; 30:599-606.

Wilson HR. Interrelationship of egg size, chick size, posthatching growth and hatchability. Word's Poultry Science Journal 1991; 47: 5-20.

Wyatt CL, Weaver WD, Beane WL. Influence of egg size, egg shell quality, and posthatch holding time on broiler performance. Poultry Science 1985; 64:2049-2055. 